\title{
Developmental Pharmacokinetics and Safety of Ibuprofen and Its Enantiomers in the Conventional Pig as Potential Pediatric Animal Model
}

\author{
Joske Millecam ${ }^{1}$, Thomas van Bergen², Stijn Schauvliege 2, Gunther Antonissen', \\ Ann Martens ${ }^{2}$, Koen Chiers ${ }^{3}$, Ronette Gehring ${ }^{4}$, Elke Gasthuys ${ }^{5}$, Johan Vande Walle ${ }^{5}$, \\ Siska Croubels ${ }^{1}$ and Mathias Devreese ${ }^{1 *}$
}

'Laboratory of Pharmacology and Toxicology, Department of Pharmacology, Toxicology and Biochemistry, Faculty of Veterinary Medicine, Ghent University, Ghent, Belgium, ${ }^{2}$ Department of Surgery and Anesthesiology of Domestic Animals, Faculty of Veterinary Medicine, Ghent University, Ghent, Belgium, ${ }^{3}$ Department of Pathology, Bacteriology and Avian Diseases, Faculty of Veterinary Medicine, Ghent University, Ghent, Belgium, ${ }^{4}$ Institute for Risk Assessment, Faculty of Veterinary Medicine, Utrecht University, Utrecht, Netherlands, ${ }^{5}$ Department of Internal Medicine and Pediatrics, Faculty of Medicine and Health Sciences, Ghent University, Ghent, Belgium

OPEN ACCESS

Edited by:

Roberto Paganelli, Università degli Studi G. d'Annunzio

Chieti e Pescara, Italy

Reviewed by: Marzia Del Re,

University of Pisa, Italy Gabriele Stocco,

University of Trieste, Italy

*Correspondence: Mathias Devreese Mathias.Devreese@ugent.be

Specialty section: This article was submitted to Translational Pharmacology, a section of the journal Frontiers in Pharmacology

Received: 07 February 2019 Accepted: 23 April 2019

Published: 09 May 2019

Citation:

Millecam J, van Bergen T, Schauvliege $S$, Antonissen $G$, Martens A, Chiers K, Gehring R,

Gasthuys $E$, Vande Walle J, Croubels S and Devreese M (2019)

Developmental Pharmacokinetics

and Safety of Ibuprofen and lts Enantiomers in the Conventional Pig as Potential Pediatric Animal Model.

Front. Pharmacol. 10:505.

doi: 10.3389/fphar.2019.00505
Pediatric drug development, especially in disease areas that only affect children, can be stimulated by using juvenile animal models not only for general safety studies, but also to gain knowledge on the pharmacokinetic and pharmacodynamic properties of the drug. Recently, the conventional growing piglet has been suggested as juvenile animal model. However, more studies with different classes of drugs are warranted to make a thorough evaluation whether the juvenile pig might be a suitable preclinical animal model. Ibuprofen is one of the most widely used non-steroidal anti-inflammatory drugs in human. The present study determined the PK parameters, gastro-intestinal and renal safety of $5 \mathrm{mg} / \mathrm{kg}$ BW ibuprofen after single intravenous, single oral and multiple oral administration to each time eight pigs (four males, four females) aging 1, 4, 8 weeks and 6-7 months. Oral administration was performed via a gastrostomy button. A jugular catheter was used for intravenous administration and blood sampling. To assess NSAID induced renal toxicity, renal function was evaluated using iohexol and $p$-aminohippuric acid as markers for glomerular filtration rate and renal plasma flow, respectively. After the trial, necropsy and histology was performed to evaluate macroscopic and microscopic gastro-intestinal as well as renal lesions. Both enantiomers, R-ibuprofen and S-ibuprofen, were determined in plasma using an inhouse developed and validated UHPLC-MS/MS method. Pharmacokinetic parameters were estimated using compartmental analysis. Clearance and volume of distribution of total ibuprofen and both enantiomers increased with age as was observed in human. The rate of stereochemical conversion decreased with age. Multiple oral dosing decreased the absolute oral bioavailability and maximum plasma concentration of R-ibuprofen and food consumption did not influence drug absorption. Based on the limited available pediatric literature, the current study might suggest the conventional pig as suitable animal model to evaluate NSAIDs for pediatric use. 


\section{INTRODUCTION}

Since the implementation of the Pediatric Investigation Plan (PIP) and the Pediatric Safety Plan (PSP) by, respectively, the European Medicines Agency (EMA) and the Food and Drug Administration (FDA), the number of clinical trials in children increased, leading to more and better availability of medicines for children. However, since the PIP and PSP are driven from the adult drug development path, little progress has been made in diseases that only affect children or where the disease shows biological differences between adults and children (Califf, 2016; EMA, 2017). The use of juvenile animal models might bridge that gap. Despite the increase in juvenile animal trials thanks to the pediatric legislations, almost all juvenile studies mentioned in the PIPs from 2007 to mid-2017 were general toxicology studies (Baldrick, 2018). Besides toxicology studies, there is a need for more pharmacokinetic (PK) and pharmacodynamic (PD) juvenile studies in the desired age category without any previous adult human or animal data. This would stimulate pediatric drug development in diseases that only affect children, or have a different pathogenesis compared to adults. Selecting the most appropriate animal species is crucial and the rat (57.5\%) is still the most commonly used juvenile species, followed by $\operatorname{dog}(8 \%)$, mouse $(4.5 \%)$, monkey $(4 \%)$, pig $(2 \%)$, sheep $(1 \%)$, rabbit $(1 \%)$, and hamster $(0.5 \%)$. Unfortunately, in $21.5 \%$ of the cases, no species was mentioned (Baldrick, 2018). However, this does not mean that the rat is the most appropriate animal model to evaluate pediatric PK/PD and safety characteristics. The rat is often preferred due to the availability of a large historical dataset (De Schaepdrijver et al., 2013). Nevertheless, selection of the animal species should be based on anatomical and physiological developmental similarities and differences between the juvenile animal and the pediatric population of interest, technical requirements, and the properties of the drug (De Schaepdrijver et al., 2013).

Although the conventional pig is not yet readily used in preclinical research, $\mathrm{PK} / \mathrm{PD}$ and safety studies for adults have already been performed successfully (Swindle et al., 2012; Helke and Swindle, 2013; Yoshimatsu et al., 2016). Pigs do display a high level of anatomical and physiological similarities with human regarding the organs involved in absorption, distribution, metabolism and excretion (ADME) of drugs. Moreover, growing piglets display similar maturational processes as seen in children (Gasthuys et al., 2016, 2017a; Millecam et al., 2018). Recently, Gasthuys et al. (2018) performed a PK/PD study of desmopressin in growing piglets and found the piglet to be an appropriate animal model to predict the clearance of desmopressin in humans. Nevertheless, other drug classes need to be evaluated to verify whether the growing piglet might be a good model for the pediatric population in general.

It has been over 50 years since the discovery of the nonsteroidal anti-inflammatory drug (NSAID) ibuprofen (IBU). Due to its relatively low risks for gastro-intestinal, hepato-renal, and other adverse events at over-the-counter doses ( $<1200 \mathrm{mg} /$ day), a short elimination half-live compared to other NSAIDs and thus little propensity to accumulate systemically, IBU is one of the most used drugs for treatment of acute pain and fever in humans (Rainsford, 2011). In children, the use of IBU is approved from 3 months old onwards and is widely used for the same indications as in adults, namely treatment of inflammation, mildto-moderate pain and fever. Safety and efficacy studies are widely available in the pediatric population, but specific PK studies are limited, especially regarding the enantiomers of IBU. On top of that, most studies report general mean values of PK parameters for the study population as a whole with a broad age range of included children or they have arbitrary age groups making it difficult to correctly interpret the data. Moreover, a detailed and reliable plasma concentration/therapeutic effect relationship for IBU in the pediatric population is currently lacking (de Martino et al., 2017). A thorough understanding of the developmental PK parameters could provide more information regarding the occurrence of adverse events and lead to better prediction of efficacy. Especially since S-ibuprofen (S-IBU) is the pharmacologically active enantiomer and each enantiomer can lead to different adverse events. In general, the limited PK data available do suggest similar PK properties between children younger than 12 years of age and young-tomiddle aged adults (Rainsford, 2009). Rey et al. (1994) found the plasma concentrations of S-IBU to be lower than those of R-ibuprofen (R-IBU) in infants (6-18 months of age), indicating impaired conversion from R- to S-IBU and/or higher clearance of S-IBU. The clearance rate is believed to be higher in children up to about 5 years of age and declines in older age groups (Rainsford, 2009). As it is from an ethical point of view difficult to perform full PK studies in growing children, the conventional piglet might be a good substitute to gain this developmental PK data.

The aim of the current study was to determine the PK parameters of IBU after single intravenous, single oral and multiple oral administrations at therapeutic doses in conventional pigs of different ages. Next, gastro-intestinal and renal toxicity was evaluated to assess whether IBU could be safely administered to pigs as a model for children. All trials were performed in pigs aging 1, 4, 8 weeks and 6-7 months. These age groups correspond with the main age categories of the human pediatric population, namely neonate, infant, child, and adolescent (Gad, 2015; Gasthuys et al., 2016).

\section{MATERIALS AND METHODS}

\section{Animals}

The current study was approved by the ethical committee of the Faculties of Veterinary Medicine and Bioscience Engineering of Ghent University (EC2016/105). Care and use of the animals were in full compliance with the national and European legislation on animal welfare and ethics (EurLex, 2010; Flemish Government, 2017). Four age categories were included in the study corresponding with the main age groups of the human pediatric population, namely neonate, infant, child, and adolescent (Gad, 2015; Gasthuys et al., 2016). One-week-old piglets $(3.0 \pm 0.4 \mathrm{~kg}$ BW; Landrace $\times$ Large White $\times$ Maximus, RA-SE Genetics, Merkem, Belgium), 4-week-old piglets $(7.0 \pm 0.8 \mathrm{~kg}$ BW; Maximus, RA-SE Genetics, Bassilly, Belgium), 8-week-old piglets $(20.1 \pm 3.4 \mathrm{~kg}$ 
BW; Landrace $\times$ Large White, RA-SE Genetics and Convis, Ettelbruck, Luxembourg) and 6-7-months-old pigs (134 $\pm 4.6 \mathrm{~kg}$ BW for males and $142 \pm 9.8 \mathrm{~kg}$ for females; Landrace $\times$ Large White, RA-SE Genetics and Convis, Ettelbruck, Luxembourg) were used representing the latter human age groups, respectively. Each age category consisted of 12 pigs ( $6 \sigma^{\top} / 6$ o), of which 8 pigs $\left(4 \sigma^{\top} / 4\right.$ o $)$ received ibuprofen and 4 pigs $\left(\begin{array}{lll}2 & \sigma^{x} / 2\end{array}\right)$ served as control. The pigs were randomly allocated to a treatment group taking an equal distribution of sex in all groups into account. All male pigs were intact. Since male and female pigs reach puberty at different ages and the influence of sex hormones on the PK of ibuprofen was of interest, the six male pigs were 6 months old, while the six female pigs were 7 months old (Van den Broeke et al., 2015). All pigs arrived at least $24 \mathrm{~h}$ prior to surgery at the test facility and were group-housed before surgical procedures in rescue decks (0.90 m × $1.40 \mathrm{~m}$, Provimi, Rotterdam, Netherlands) (1-week-old), standard pig stables with partially slatted floors $(2.30 \mathrm{~m} \times 2.40 \mathrm{~m})(3.5$ and 8 weeks $)$ or sow stables $(0.65 \mathrm{~m} \times 2.20 \mathrm{~m})(6-7$ months-old $)$. A double lumen catheter was placed in the jugular vein and a gastrostomy button was inserted to facilitate blood sampling and multiple oral dosing, respectively according to Gasthuys et al. (2017b) and Millecam et al. (unpublished). After surgery, the animals were housed individually to avoid pen mates biting the catheters. All age groups had ad libitum access to feed (1 week: RescueMilk ${ }^{\circledR}$, Provimi; 3.5 and 8 weeks: Biggistart Opti ${ }^{\circledR}$, Aveve, Leuven, Belgium; 6-7 months: Optivo Pro ${ }^{\circledR}$, Aveve) and water. Natural light was provided by translucent windows and the stable temperature was $24.3 \pm 2.1^{\circ} \mathrm{C}$ during the whole conduct of the trials. Higher temperatures $\left(30-35^{\circ} \mathrm{C}\right)$ in the rescue decks were obtained by heating lamps. One day prior to surgery, a cotton towel was given to the piglets (youngest three age categories) which was then passed on after surgery to mimic the smell of the other piglets when they were singly housed. The 1-week-old pigs could also hear, smell and see $\left(\right.$ Plexiglass $\left.{ }^{\circledR}\right)$ each other. All stables were enriched with suspension chains, rubber toys, and balls which were rotated on a daily basis.

Prior and after surgery, all pigs were weighed on a daily basis for the whole conduct of the trial (10 days), except the 6-7 months old pigs who were only weighed the day of surgery. The pigs were intensively socialized to facilitate the handling with the catheter and button. Both lumens of the jugular catheter were flushed at least once daily with a sterile diluted heparin solution (1-week-old piglets: $0.04 \% \mathrm{v} / \mathrm{v}$; 4 - and 8 -week-old piglets: $1 \% \mathrm{v} / \mathrm{v} ; 6-7$-months-old pigs: $2 \%$ $\mathrm{v} / \mathrm{v})$. Sealing caps and bandages were changed when needed and wound healing was monitored. The stomach button was flushed daily with tap water and the skin surrounding the stoma was visually inspected on a daily basis. The water and feed intake, body temperature and interaction with animal caretakers were monitored twice daily. Temperature was measured via a LifeChip $^{\circledR}$ (Allflex Europe SA, Vitré, France) placed in the left semitendinosus muscle during anesthesia. To evaluate possible early signs of inflammation, total white blood cell (WBC) count was performed daily, from the day after surgery till the end of the trial by taking $1 \mathrm{~mL}$ blood via the double lumen catheter in an $\mathrm{K}_{3}$ EDTA collection tube (Vacutest ${ }^{\circledR}$ Kima, Arzergrande, Italy). White blood cell count was performed by Medvet BVBA (Antwerp, Belgium). If the piglets showed more apathy and had a body temperature $\geq 40^{\circ} \mathrm{C}$, they were treated with an intramuscular injection of $0.4 \mathrm{mg} / \mathrm{kg} \mathrm{BW}$ of meloxicam (Metacam ${ }^{\circledR} 5 \mathrm{mg} / \mathrm{mL}$, Boehringer Ingelheim Vetmedica $\mathrm{GmbH}$, Ingelheim am Rhein, Germany).

\section{Experimental Design of the Ibuprofen PK Study}

The experimental design was identical for all four age categories and is graphically shown in Figure 1. The control pigs did not receive any IBU during the trial, but were sham-treated with water or $\mathrm{NaCl}$ solution for the oral and IV administration, respectively. After surgery, the pigs had 1 day to recover before the single dose intravenous PK study of $5 \mathrm{mg} / \mathrm{kg} \mathrm{BW}$ IBU (Ibuprofenum, 50/50 ratio R/S-IBU, Fagron, Inc., Meer, Belgium) was initiated. The drug was dissolved in $0.9 \% \mathrm{NaCl}$ (stock solution of $100 \mathrm{mg} / \mathrm{mL}$ ) and administered IV using the proximal lumen of the jugular catheter. Next, one wash-out day was respected before starting the multiple dosing study with a pediatric IBU suspension $(5 \mathrm{mg} / \mathrm{kg} \mathrm{BW}$; Ibuprofen $\mathrm{EG}^{\circledR} 40 \mathrm{mg} / \mathrm{mL}, 50 / 50$ ratio R/S-IBU, Eurogenerics, Brussels, Belgium). All pigs were fasted overnight before the first oral IBU administration, except for the 1-week-old piglets. The youngest age group was deprived of milk only $1 \mathrm{~h}$ before administration due to the risk of hypoglycemia. All pigs had again access to feed one and a half hour after administration (p.a.). Ibuprofen was given three times a day for five consecutive days. The dose interval was $6 \mathrm{~h}$ between the morning and the noon dose and between the noon and the evening dose. After each oral dose, the gastric tube was flushed with tap water $(\geq 5 \mathrm{~mL})$ to make sure all IBU entered the stomach. The control pigs received the same amount of tap water each time. Venous blood samples for PK analysis were taken on different time points through the distal lumen of the jugular catheter. The day of IV administration, blood was taken prior to and 5, 10, 20, 30, 45, $60 \mathrm{~min}$ and 1.5, 2, 2.5, 3, 4, 6, 8, and $24 \mathrm{~h}$ p.a. For oral multiple dose PK analysis, blood samples were drawn each time right before and $30 \mathrm{~min}$ p.a., except for the first (single dose fasted) and 13th (not fasted) oral dose where a full $\mathrm{PK}$ profile was obtained by more frequent sampling $(0,5,10$, 20, 30, 45, $60 \mathrm{~min}$ and 1.25, 1.5, 1.75, 2, 2.5, 3, 4, and $6 \mathrm{~h}$ p.a.). All blood samples were transferred into $4 \mathrm{~mL} \mathrm{~K} \mathrm{~K}_{3}$ EDTA collection tubes, immediately kept on ice and centrifuged for $10 \mathrm{~min}$ at $2095 \mathrm{~g}$. Plasma was aliquoted, frozen and stored at $<-15^{\circ} \mathrm{C}$ until analysis. Analytical determination of both IBU enantiomers was performed by an in-house developed and validated UHPLC-PDA method which is described in the Supplementary Material. On day 10, all pigs were euthanized by an IV injection of an overdose of pentobarbital (Sodium pentobarbital $20 \%{ }^{\circledR}$, Kela, Hoogstraten, Belgium). When the double-lumen catheter was no longer functional, euthanasia was performed by intramuscular injection with a mixture (1:1, $0.22 \mathrm{~mL} / \mathrm{kg}$ ) of xylazine hydrochloride (Xyl-M 2\% ${ }^{\circledR}$, VMD, Arendonk, Belgium) and tiletamine-zolazepam (Zoletil 100 ${ }^{\circledR}$, 


\section{$\begin{array}{cccccccc}\text { Surgery } & \text { PK IV } & \text { PK PO } & \text { PK PO } & \text { PK PO } & \text { PK PO } & \text { PK PO } & \text { Safety } \\ \text { Day 1 } & \text { Day 3 } & \text { Day 5 } & \text { Day 6 } & \text { Day 7 } & \text { Day 8 } & \text { Day 9 } & \text { Day } 10\end{array}$

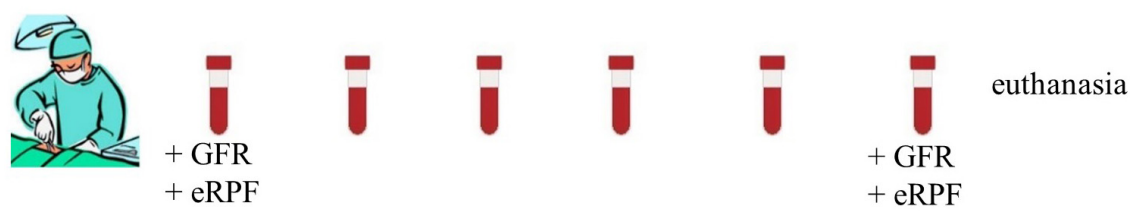

3 intragastric doses per day with ibuprofen or water

FIGURE 1 | Graphical overview of the experimental setup. In total, 12 animals (PK: 4 o7 , 4 o; control: $2 \sigma^{7}$, 2 o) per age category (1, 4, 8 weeks and 6-7 months old) underwent surgery. The single intravenous dose (IV) ibuprofen was $5 \mathrm{mg} / \mathrm{kg} \mathrm{BW}$ and the oral dose (PO) was $5 \mathrm{mg} / \mathrm{kg}$ three times a day. On day three and day 9 , the glomerular filtration rate (GFR) and estimated renal plasma flow (eRPF) were determined.

Virbac, Netherlands) followed by intracardiac injection of an overdose of pentobarbital.

\section{Evaluation of Gastro-Intestinal and Renal Toxicity}

Possible physiological changes in kidney function were evaluated by measuring the glomerular filtration rate (GFR) and estimated renal plasma flow (eRPF) on the first day of IBU administration IV and the last day of the oral administration (Figure 1). GFR was measured through a single dose of $64.7 \mathrm{mg} / \mathrm{kg} \mathrm{BW}$ of iohexol $\left(0.1 \mathrm{~mL} / \mathrm{kg}\right.$ BW, Omnipaque ${ }^{\circledR} 300 \mathrm{mg} \mathrm{I} / \mathrm{mL}$, GE Healthcare, Belgium). Estimated RPF was determined via a single dose of $10 \mathrm{mg} / \mathrm{kg}$ BW of $p$-aminohippuric acid (PAH, stock solution of $200 \mathrm{mg} / \mathrm{mL}$ in $0.9 \% \mathrm{NaCl}$ solution, Sigma-Aldrich, Overijse, Belgium). Sampling points overlapped with those of IBU and were taken right before administration and 5, 10, 30, $60 \mathrm{~min}$ and $2,3,6$, and $8 \mathrm{~h}$ after administration. Determination of iohexol and PAH in porcine plasma was performed using a validated UHPLC-MS/MS method (Dhondt et al., 2019). A more detailed description of this analytical method is given in the Supplementary Material.

During necropsy, macroscopic lesions were evaluated in the stomach and kidneys. The stomach was removed and opened along the greater curvature. After discarding stomach contents and rinsing the mucosa with water, possible macroscopic gastric lesions were scored according to the Lanza score (Table 1) (Lanza et al., 1985). Small samples of duodenum, jejunum, ileum, pars oesophagea, antrum, fundus, left and right kidney were fixed in $4 \%$ formaldehyde, embedded in paraffin, sectioned at $5 \mu \mathrm{m}$ and stained with hematoxylin and eosin (HE) according to standard techniques. The grading scale for histological examination of the gastro-intestinal samples is given in Table $\mathbf{1}$ and adapted from Geboes et al. (2000). The samples were blinded before scoring. Renal samples were microscopically evaluated for papillary necrosis.

\section{Pharmacokinetic Analysis}

All PK analyses were performed in Phoenix version 8.1 (Certara, Princeton, NJ, United States). Values below the LOQ of $0.25 \mu \mathrm{g} / \mathrm{mL}$ were excluded from the analysis. A 1-compartmental model was built taking the systemic conversion of $\mathrm{R}$ - to
TABLE 1 | Macroscopic and microscopic grading scale for the gastro-intestinal samples (Lanza et al., 1985; Geboes et al., 2000).

\begin{tabular}{ll}
\hline $\begin{array}{l}\text { Macroscopic } \\
\text { grade }\end{array}$ & \\
\hline 0 & Intact mucosa \\
1 & Redness and hyperemia in the mucosa \\
2 & One or two erosions or hemorrhaging lesions \\
3 & 3-10 erosions or hemorrhaging lesions \\
4 & $>10$ erosions or hemorrhaging lesions \\
Microscopic & \\
grade & \\
Grade 1 & Lymphoid follicles in mucosae and submucosae \\
Subgrade 1.0 & No increase in lymphoid aggregates or follicles \\
Subgrade 1.1 & Moderate increase in lymphoid aggregates $(<5)$ \\
Subgrade 1.2 & Severe increase in lymphoid aggregates $(\geq 5)$ and/or 1 \\
Subgrade 1.3 & lymphoid follicle \\
Grade 2 & $\geq 2$ lymphoid follicles \\
Subgrade 2.0 & Chronic inflammatory infiltrate in lamina propria \\
Subgrade 2.1 & No infiltration \\
Subgrade 2.2 & Mild infiltration \\
Subgrade 2.3 & Moderate infiltration \\
Grade 3 & Severe infiltration \\
Subgrade 3.0 & Erosion or ulceration \\
Subgrade 3.1 & No erosion, ulceration, or granulation tissue \\
Subgrade 3.2 & Recovering epithelium + adjacent inflammation \\
Subgrade 3.3 & Probable erosion - focally stripped \\
Subgrade 3.4 & Unequivocal erosion \\
& Ulcer or granulation tissue \\
\end{tabular}

S-ibuprofen (R-to-S-IBU) into account (Figure 2). The dose of the individual enantiomers was considered half of the racemic dose of $5 \mathrm{mg} / \mathrm{kg} \mathrm{BW}$. Chiral inversion (Cl R to S) was estimated after IV administration and this value was fixed to estimate values of the PK parameters after oral administration. The plasma concentrations of total IBU were calculated from the sum of R- and S-IBU. The following primary and secondary PK parameters were calculated for IV and PO administration for total IBU, R- and S-IBU: clearance (IV only, Cl), apparent volume of distribution (IV only, $\mathrm{V}_{\mathrm{d}}$ ), area under the plasma concentration time curve from time 0 and extrapolated to infinity $\left(\mathrm{AUC}_{0 \rightarrow \infty}\right)$, maximum plasma concentration for PO $\left(\mathrm{C}_{\max }\right)$, 


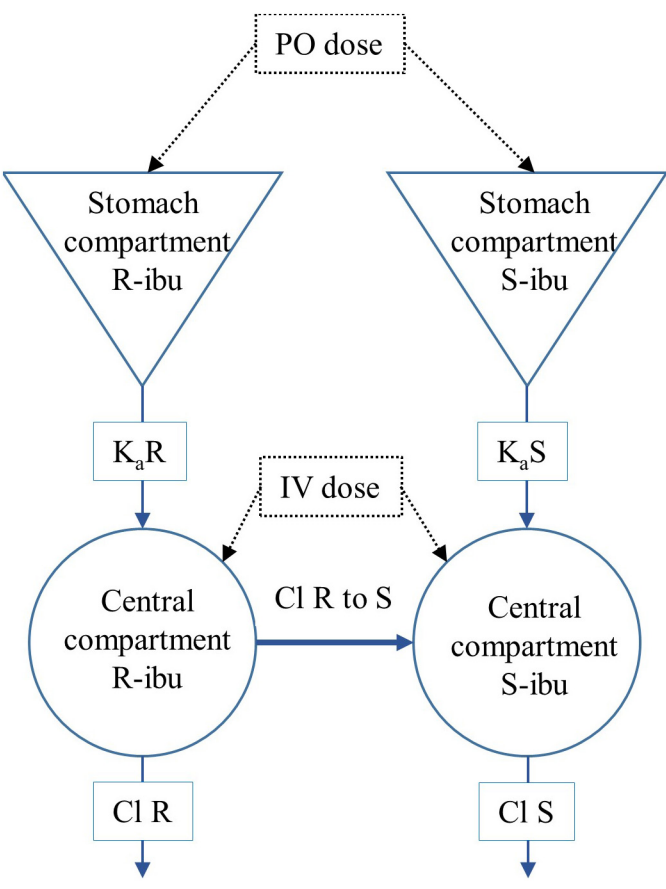

FIGURE 2 | Representation of the 1-compartmental model for R- and S-ibuprofen (R-IBU and S-IBU). CI R to S represents the systemic conversion of R-ibuprofen to S-ibuprofen.

plasma concentration at time 0 for IV $\left(\mathrm{C}_{0}\right)$, time to maximum plasma concentration $\left(\mathrm{T}_{\max }\right)$, elimination half-life $\left(\mathrm{T}_{1 / 2}\right)$ and absorption rate constant $\left(\mathrm{k}_{\mathrm{a}}\right)$.

The absolute oral bioavailability (F) was estimated for every individual pig from the ratio of the areas under the plasma concentration time curve from time 0 to $3 \mathrm{~h}\left(\mathrm{AUC}_{0 \rightarrow 3 \mathrm{~h}}\right)$ after $\mathrm{PO}$ and IV administration, calculated by non-compartmental analysis (NCA). The linear up log down trapezoidal method was used for AUC calculations.

The values of the $\mathrm{PK}$ parameters of iohexol and $\mathrm{PAH}$ were estimated using a two- and one-compartmental model, respectively. The $\mathrm{Cl}$ estimated from these models were defined as GFR and eRPF, respectively.

Allometric relationships were visually evaluated between $\mathrm{Cl}$, $\mathrm{V}_{\mathrm{d}}$, BW, GFR, and eRPF.

The accumulation ratio after multiple dosing was calculated using the $\mathrm{AUC}_{0 \rightarrow 6} \mathrm{~h}$ from the first and 13th oral dose according to Eq. 1 .

$$
\text { accumulation ratio }=\frac{A U C_{0 \rightarrow 6 h, \text { dose } 13}}{A U C_{0 \rightarrow 6 h, \text { dose } 1}}(1) .
$$

\section{Statistical Analysis}

All statistical analyses were performed in RStudio version 1.1.456 (RStudio, Inc., Boston, MA, United States). In order to evaluate the effect of age and gender on the values of different PK parameters, a one-way nested ANOVA was performed $(p<0.05)$. Normality of the data was checked using Levene's test. If the data did not met the criteria of normality $(p<0.01)$, a $\log$ transformation was performed. Post hoc analysis was done using Tukey's HSD (Honestly Significant Difference) test. Evaluation of the same PK parameter between IV and the first PO administration and between the first and fifth day of PO administration was done using a pairwise $t$-test $(p<0.05)$. The significant differences $(p<0.05)$ between the same PK parameters for R- and S-IBU were evaluated using a Student's $t$-test for every age group individually.

To evaluate differences in age and treatment group regarding gastro-intestinal and kidney lesions, a Kruskal-Wallis test was performed on the sum of the macroscopic and microscopic scoring per tissue. If the Kruskal-Wallis test was significant $(p<0.05)$, a Dunn test $(p<0.025)$ was performed as post hoc test. Since two comparisons, namely age and treatment group, were made in the Dunn test, the significance level of 0.05 was divided by two, resulting in an alpha of 0.025 . GFR and eRPF were compared between start and end of the trial for every age group using a pairwise $t$-test $(p<0.05)$. Finally, changes in body temperature and total amount of WBCs were evaluated using an univariate type III repeated-measures ANOVA. If Mauchly's sphericity test was significant $(p<0.05)$ the Greenhouse-Geisser correction was applied.

\section{RESULTS}

\section{UHPLC-PDA Method for the Determination of R- and S-Ibuprofen}

Supplementary Table S1 summarizes the validation results obtained for R-IBU and S-IBU in porcine plasma. Linear matrixmatched calibration curves with a range of $0.25-40 \mu \mathrm{g} / \mathrm{mL}$ for both enantiomers, were obtained. Good correlation between analyte concentrations and detected responses was observed for both enantiomers, with correlation coefficient ( $r$ ) values ranging between 0.9949 and 0.9991 and goodness-of-fit coefficient (gof) values between 3.66 and $9.04 \%$. The acceptance criteria for within- and between-run accuracy and precision were met for all drugs at the specified concentration levels (Supplementary Table S1). The LOQ was $0.25 \mu \mathrm{g} / \mathrm{mL}$ for both enantiomers. The calculated LOD values, corresponding with a signal/noise $(\mathrm{S} / \mathrm{N})$ ratio of 3 , were 0.128 and $0.165 \mu \mathrm{g} / \mathrm{mL}$ for $\mathrm{R}-\mathrm{IBU}$ and S-IBU, respectively. No carry-over was present as there was no analyte detected in the solvent sample injected after the highest calibrator. No interfering peaks could be detected in any of the blank samples at the retention time of the drugs, meaning the specificity of the method was demonstrated.

\section{Animals}

All pigs survived the surgery and all double lumen jugular catheters were functional the day after surgery. Six out of 48 pigs had an obstructed jugular catheter after several days or accidentally removed the catheter due to scrubbing against the wall (two control pigs and four pigs in the IBU group, on day 6 or later, except for one 8-week-old control pig who removed its catheter already 1 day after surgery). If the catheter was obstructed or removed during the trial, no further blood samples were taken. Ibuprofen however, was still given via the stomach 
button to evaluate drug safety. The day after surgery, all stomach buttons, except for one 6-month-old control pig, were functional. During the trial, one 1-week-old piglet in the IBU group (day 9), two 8-week-old piglets in the IBU group (days 5 and 8), three 6-7-month-old pigs in the IBU group (days 5, 6, and 9) and two 6-7-month-old pigs in the control group (days 1 and 2) had a dysfunctional button after several days due to obstruction or loss of the button. This also led to exclusion of the animal from the trial. If the stomach button was obstructed, it was left in place as the pigs did not seem to experience any nuisance. If the button was removed, the resulting wound was cleaned, disinfected and bandaged. Only two 1-week-old and one 4-weekold piglet, all in the control group, showed more apathy and had a body temperature $\geq 40^{\circ} \mathrm{C}$. These piglets were successfully treated with meloxicam.

No significant changes in body temperature were observed during the trial between treatment and control group or between the different age groups (Supplementary Figure S1). Similarly, no significant differences were observed in the WBC count over time for both control and treatment group. However, the 1-week-old piglets treated with ibuprofen had a significant lower amount of leukocytes compared to the control group (Supplementary Figure S1).

\section{Pharmacokinetics of R-, S-, and Total Ibuprofen \\ Total Ibuprofen}

The median plasma concentrations [ + standard deviation (SD)] and the corresponding median fit of total IBU after IV and PO administration are demonstrated in Figure 3. The PK parameters are given in Table 2. Both $\mathrm{Cl}$ and $\mathrm{V}_{\mathrm{d}}$ showed an allometric relationship with BW with an allometric coefficient of 0.97 and 0.86, respectively (Supplementary Figure S2).

Significant sex differences were only observed at the age of 67 months for $\mathrm{k}_{\mathrm{a}}$ after the first oral dose, $\mathrm{C}_{\max }$ after 5 days of IBU dosing and $\mathrm{AUC}_{0 \rightarrow 3}$ after IV administration and 5 days of oral dosing. Age did have a significant effect on all PK parameters.

\section{R- and S-Ibuprofen}

The median plasma concentrations $(+\mathrm{SD})$ for R- and S-IBU after IV and PO administration can be found in Figure 3. The estimates of the PK parameters are given in Table 2. Supplementary Figure S2 demonstrates the allometric relationship between $\mathrm{Cl}$ and $\mathrm{V}_{\mathrm{d}}$ of $\mathrm{R}$ - and $\mathrm{S}-\mathrm{IBU}$ and $\mathrm{BW}$. An allometric coefficient of $0.69,0.79,1.03$, and 0.85 was estimated for $\mathrm{Cl}$ and $\mathrm{V}_{\mathrm{d}}$ of $\mathrm{R}$ - and $\mathrm{S}$-IBU, respectively.

After IV administration, $\mathrm{C}_{0}$ was higher in the 6-7 months old pigs compared to the other age groups for both enantiomers. This might be related to the $\mathrm{V}_{\mathrm{d}}$. Hence, the $\mathrm{V}_{\mathrm{d}}$ for $\mathrm{R}$-IBU was the lowest in the 6-7 months old pigs, but a higher $V_{d}$ in the 1-weekold pigs was observed compared to the 4 -week-old pigs. Volume of distribution did not change during the first 8 weeks of life for S-IBU, but was significantly lower in the 6-7 months old pigs. No significant differences were observed between the 1-week- and 8week-old pigs or the 4-week- and 8-week-old pigs regarding $\mathrm{V}_{\mathrm{d}}$ of R-IBU. Clearance of S-IBU increased with age up until 8 weeks, after which it decreased. Clearance of R-IBU showed a sinusoidal course, namely higher in the 1-week- and 8-week-old pigs and lower in the 4-week- and 6-7-months-old pigs. The half-life of $\mathrm{S}$-IBU was the highest in the 1-week-old pigs and did not change in the other age groups. However, $\mathrm{T}_{1 / 2}$ of $\mathrm{R}-\mathrm{IBU}$ did show again the sinusoidal course similar but opposite to $\mathrm{Cl}$ of R-IBU, namely lowest in the 1-week- and 8-week-old pigs, highest in the 4-weekand 6-7-months old pigs. The AUC of S-IBU was always higher than that of R-IBU. The 1-week-old piglets had the lowest AUC for R-IBU and the AUC increased with age. The AUC of S-IBU in the 8-week-old pigs was lower compared to the other age groups.

After a single oral ibuprofen dose in the fasted state, no differences with age in $\mathrm{T}_{1 / 2}, \mathrm{k}_{\mathrm{a}}, \mathrm{T}_{\max }$, or $\mathrm{C}_{\max }$ were observed for both enantiomers. Oral bioavailability only changed with age for R-IBU with the 4-week-old pigs having the lowest $\mathrm{F}$ compared to the other age groups. The AUC of R-IBU stayed the same during the first 8 weeks of life and was higher in the 6-7 months old pigs. The AUC of S-IBU on the other hand, was lower in the 8-week-old pigs compared to the 1week- and 6-7-month-old pigs. Regarding significant differences between both enantiomers after oral dosing, only the 1-weekold piglets had a significant higher $\mathrm{T}_{\max }$ and $\mathrm{C}_{\max }$ for $\mathrm{S}-\mathrm{IBU}$ compared to R-IBU. $\mathrm{C}_{\max }$ of S-IBU at 4 weeks of age was also significant higher compared to that of R-IBU. And similar to the IV administration, the AUC of S-IBU was greater than the AUC of R-IBU in all age groups.

\section{Multiple Oral Dosing of Ibuprofen}

After 5 days dosing, few PK parameter estimates changed compared to the first oral dose (Table 3). $\mathrm{C}_{\max }$ was lower for R-IBU the last day compared to the first oral dose and $C_{\max , R}$ was lower compared to $C_{\max , S}$ for the 1-week-, 4-week-, and 8-week-old pigs. A lower $\mathrm{F}$ for R-IBU $\left(F_{R}\right)$ was also observed. In the 4-week-old pigs, the AUC of both enantiomers was significantly lower after 5 days of IBU dosing.

The mean ratio of the AUC for R-IBU, S-IBU or total IBU after the first and last dose, as calculated according to Eq. 1, was lower than 1 for all four age groups. Results of the accumulation ratio can be found in Supplementary Table S2.

\section{Safety of Ibuprofen}

Ibuprofen was well-tolerated in all pigs in every age group. During necropsy, no severe lesions could be observed in the stomach and consequently no significant differences were observed between the IBU group and the control group. Microscopic scoring revealed only significant differences between IBU and control group in the duodenum and jejunum for the 1 -week-old pigs and in the antrum for the 4 -week-old pigs. No significant histological changes were observed in the kidney. An overview of the mean sum of grading scores per tissue and group is given in Table 3.

The iohexol clearance (GFR) did not show any significant differences between the two administrations, namely at the start of the trial and after 5 days of IBU dosing, for all age groups. However, the eRPF (PAH clearance) was significantly higher at 4 weeks and 6-7 months of age. Boxplots of the results are given in Supplementary Figure S3. 

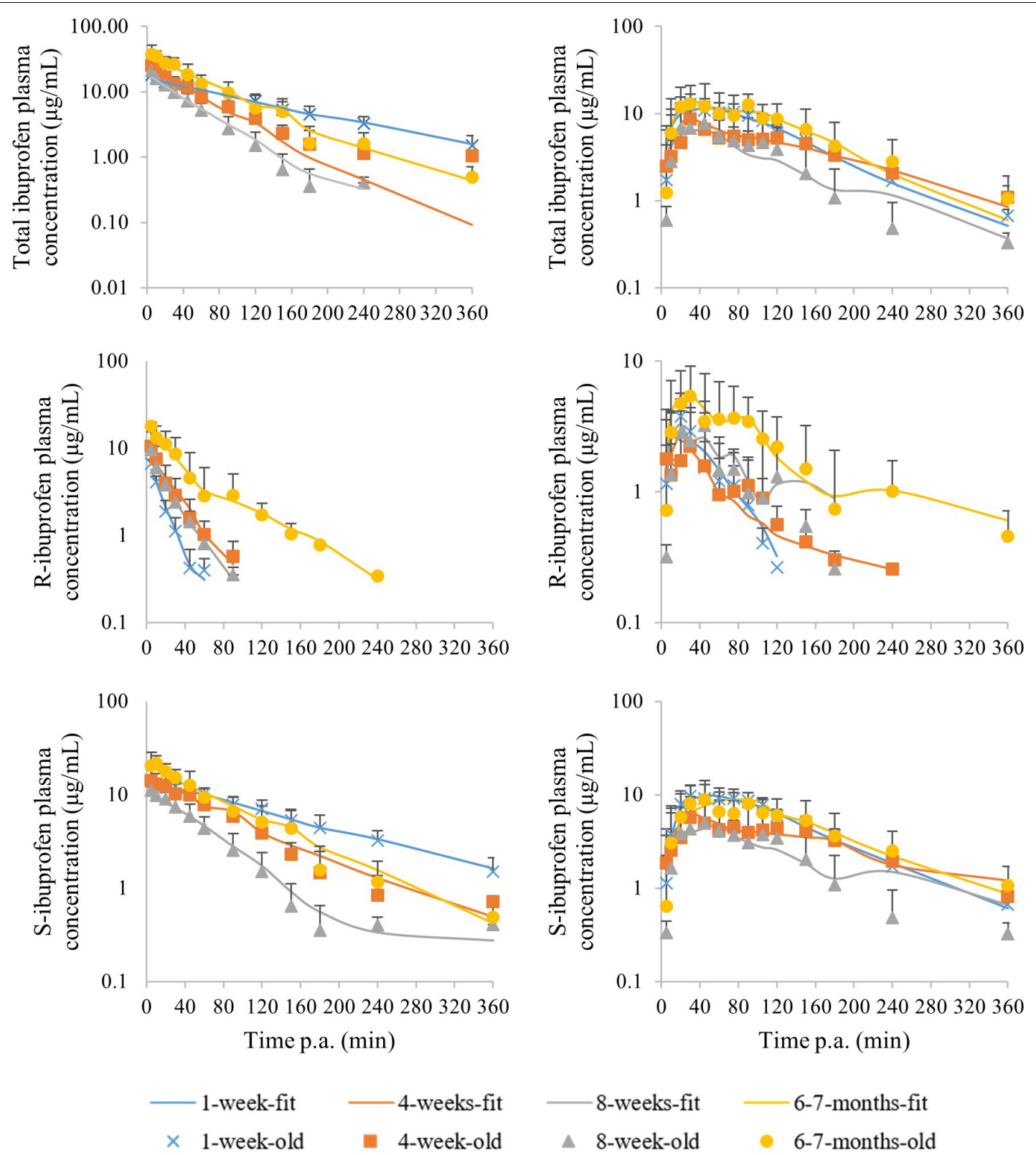

FIGURE 3 | Median (+ standard deviation) plasma concentrations of total ibuprofen (top), R-ibuprofen (middle) and S-ibuprofen (bottom) after intravenous (left) and oral (right) administration of racemic ibuprofen ( $5 \mathrm{mg} / \mathrm{kg} \mathrm{BW}$ ) to each time 8 (4 o , 4 o) pigs aging 1 week (blue cross), 4 weeks (orange square), 8 weeks (gray triangle) and 6-7 months (yellow dot). The lines are the corresponding median model fits using the PK model.

The eRPF showed a good correlation with GFR which is reflected in almost identical allometric coefficients when $\mathrm{Cl}$ is plotted against GFR or eRPF (Supplementary Figure S2).

\section{DISCUSSION}

The current study aimed to evaluate developmental changes in pharmacokinetic parameters of R-, S-, and total ibuprofen in growing conventional pigs after single intravenous, single oral and multiple oral administration, as well as the drug's safety profile.

\section{Developmental Pharmacokinetics of Total Ibuprofen in Pigs}

The absorption of IBU in the fasted state was significantly faster in the 1-week-old and 6-7 months old pigs compared to the other two age groups. In the 6-7 months old pigs, this is probably due to the greater contact surface area. In neonatal pigs however, the gastric $\mathrm{pH}$ is higher compared to older pigs. A higher $\mathrm{pH}$ would 


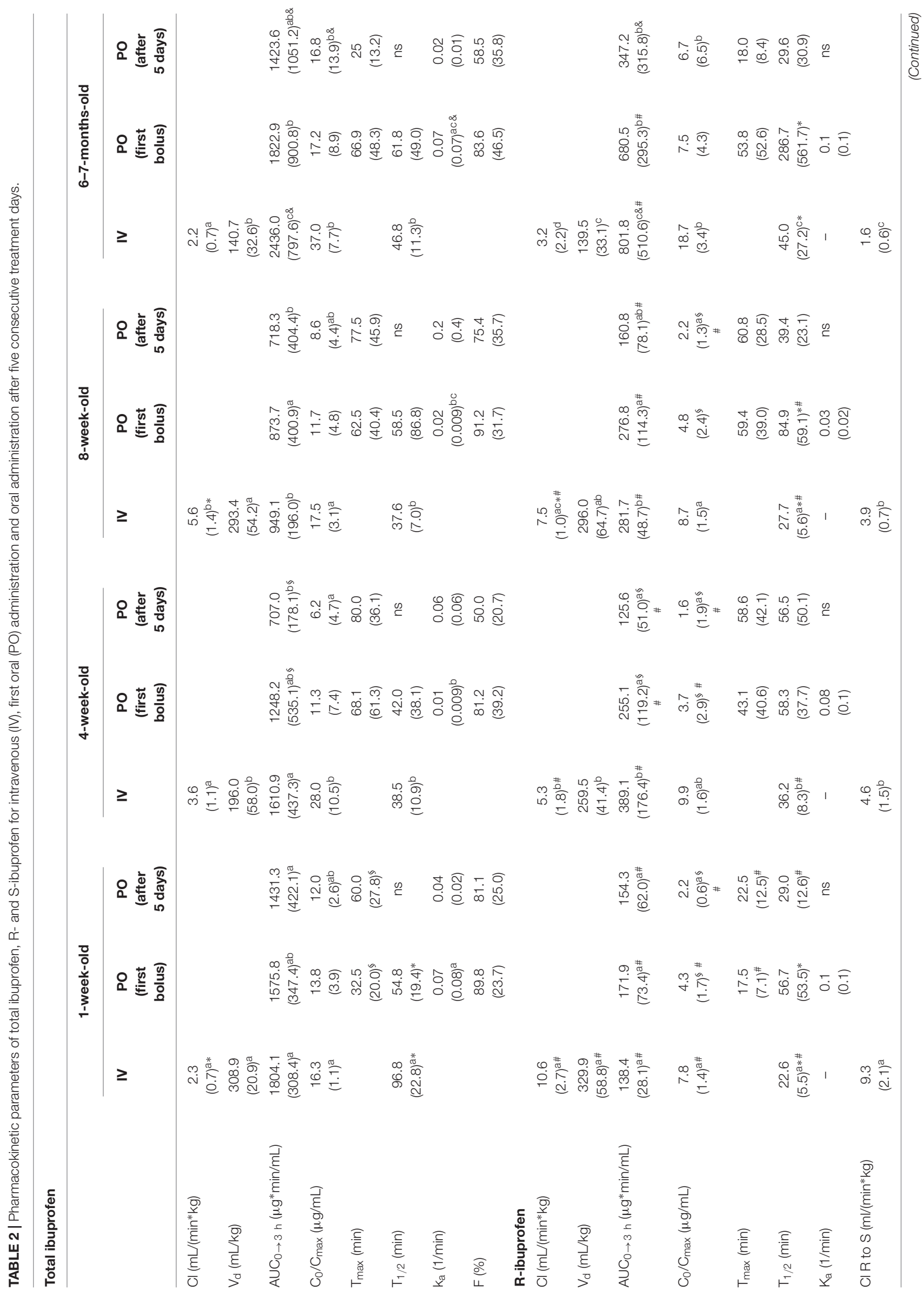




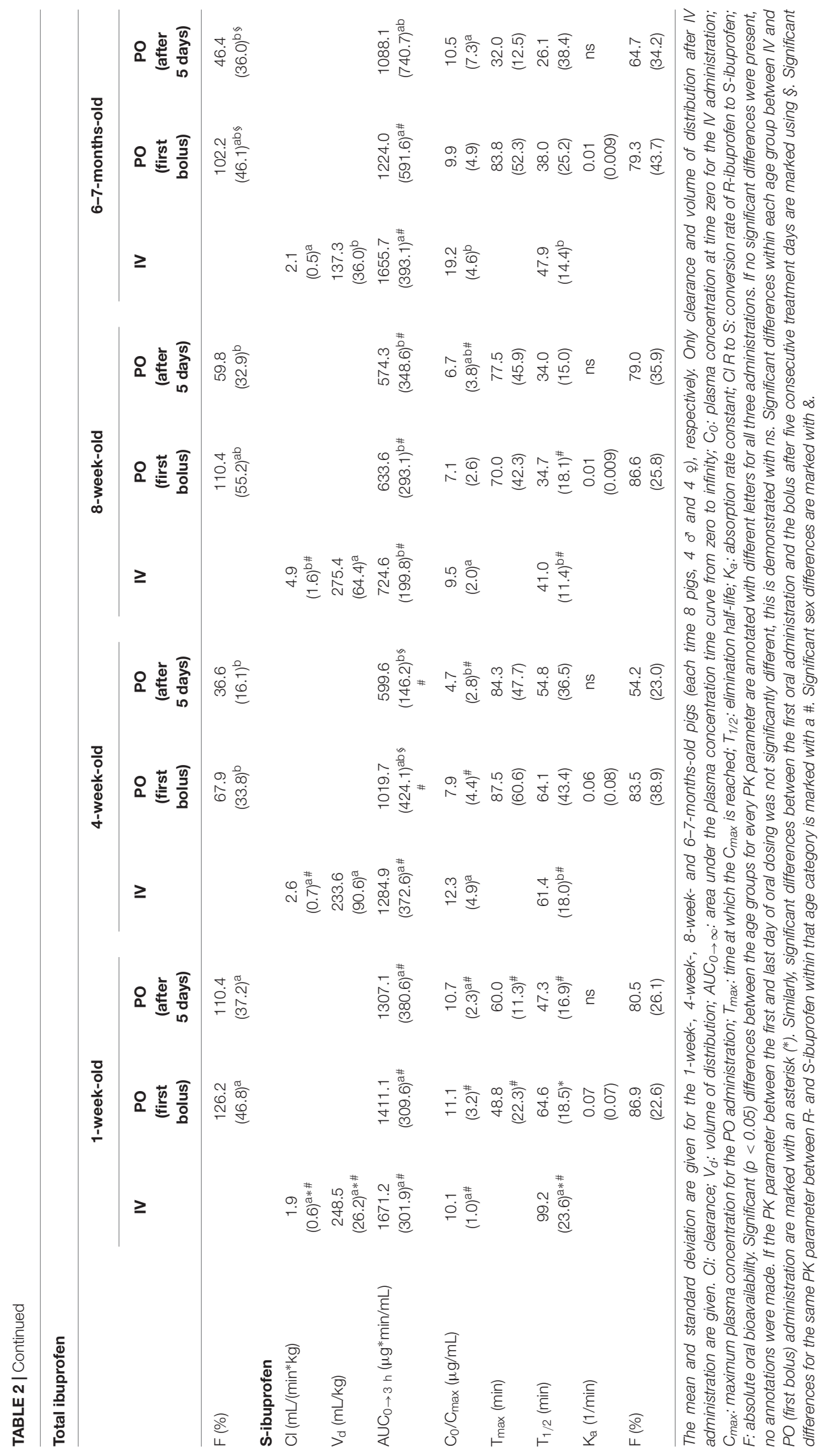




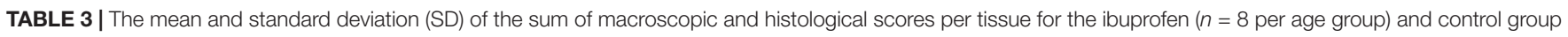
( $n=4$ per age group) for the 1-week-, 4-week-, 8-week- and 6-7-months-old pigs.

\begin{tabular}{|c|c|c|c|c|c|c|c|}
\hline & Duodenum & Jejunum & Ileum & Pars oesophagea & Antrum & Fundus & Macroscopic score \\
\hline \multicolumn{8}{|c|}{ 1-week-old pigs } \\
\hline Ibuprofen & $1.38(0.52)^{*}$ & $3.63(2.88)^{*}$ & $5.13(0.99)$ & $1.75(2.19)$ & $2.13(1.13)$ & $4.0(1.77)$ & $0.25(0.46)$ \\
\hline Control & $4(1.63)^{*}$ & $1.25(0.50)^{*}$ & $5.25(0.50)$ & $1.75(1.50)$ & $3.50(1.73)$ & $5.0(1.41)$ & $0(0)$ \\
\hline \multicolumn{8}{|c|}{ 4-week-old pigs } \\
\hline Ibuprofen & $3.50(2.22)$ & $3.63(0)$ & $3.13(0)$ & $3.75(2.22)$ & $2.75(0.50)^{*}$ & $0.75(1.91)$ & $2.13(0.58)$ \\
\hline Control & $4.75(2.22)$ & $3.0(0)$ & $3.0(0)$ & $1.75(2.22)$ & $5.25(0.50)^{*}$ & $1.50(1.91)$ & $1.50(0.58)$ \\
\hline \multicolumn{8}{|c|}{ 8-week-old pigs } \\
\hline Ibuprofen & $3.75(0.71)$ & $4.88(1.64)$ & $6(0)$ & $2.13(1.55)$ & $2.38(1.69)$ & $2.75(1.16)$ & $2.25(1.04)$ \\
\hline Control & $4.0(0.82)$ & $4.25(2.06)$ & $6(0)$ & $1.25(0.50)$ & $2.75(0.96)$ & $2.75(1.71)$ & $3.0(0.82)$ \\
\hline \multicolumn{8}{|c|}{ 6-7-months-old pigs } \\
\hline Ibuprofen & $3.25(1.16)$ & $3.38(1.69)$ & $6.38(0.74)$ & $4.50(3.66)$ & $2.88(2.42)$ & $2.13(1.96)$ & $1.75(0.71)$ \\
\hline Control & $4.0(0.82)$ & $3.25(1.89)$ & $6.25(0.50)$ & $3.75(3.77)$ & $3.75(1.71)$ & 2.25 (1.89) & $1.25(0.50)$ \\
\hline
\end{tabular}

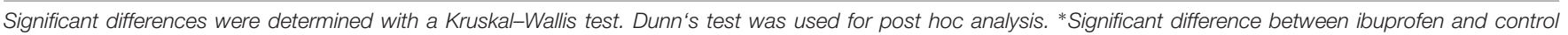
group within that age group ( $p<0.025)$.

normally lead to less passive absorption in combination with a weak acid drug such as ibuprofen ( $\mathrm{pKa}=5.3$ ) (Walthall et al., 2005). Nevertheless, since the 1 -week-old piglets drank milk $1.5 \mathrm{~h}$ before administration, it is possible that the $\mathrm{pH}$ was lower leading to a faster absorption. The maturational changes in PK estimates will be discussed by means of the IV data. The $\mathrm{Cl}$, when expressed per $\mathrm{kg}$ BW, increased with age up until 8 weeks of age, after which it decreased again (6-7 months old). Since IBU is known to be primarily metabolized in the liver, the maturation of CYP enzymes will be a defining factor for $\mathrm{Cl}$ as IBU is extensively metabolized by CYP2C8 and CYP2C9 in human (Rainsford, 2009). The homologs porcine CYP2C enzymes did increase with age in conventional pigs from a neonatal age till 8 weeks of age. Moreover, the amount of CYP2C35 in liver microsomes was lower in the 6-7 months old pigs compared to the 8week-old pigs. This strengthens the suggestion that CYP2C35 might be involved in the biotransformation of IBU (Millecam et al., 2018). The $\mathrm{Cl}$ of IBU will also be influenced by the liverto-body weight ratio (Rainsford, 2009). Millecam et al. (2018) suggested a log linear relationship between liver and body weight in conventional pigs from birth till puberty, with a maximum BW of $124 \mathrm{~kg}$. In contrast, Hu (2015) observed a decreasing liver-to-body weight ratio after 5 weeks of age in Camborough29 pigs. Since the oldest pigs in the current study all weighed more than $124 \mathrm{~kg}$ and the $\mathrm{Cl}$ is lower compared to the younger pigs, it is believed that the liver to body weight ratio would be much lower compared to these younger pigs. Hence, the observed non-linear relationship between non-weight-normalized $\mathrm{Cl}$ and weight do support these findings (Supplementary Figure S2). In human, the liver-to-body weight ratio also follows a non-linear curve with aging ('t Jong, 2014). At last, both GFR and eRPF were significantly lower in the 6-7 months old pigs compared to the 8 -week-old pigs. Since the metabolites of IBU are primarily renally excreted, these low renal physiological parameters will contribute to the lower $\mathrm{Cl}$ observed in these oldest pigs. The observed relationship between $\mathrm{Cl}$ and GFR and eRPF is then also almost linear (Supplementary Figure S2).
The $\mathrm{V}_{\mathrm{d}}$, expressed per kg BW, showed a sinusoidal course with age, with the highest observed $V_{d}$ in the 1-week- and 8-week-old pigs. These differences are probably due to the combination of maturation of the drug binding protein, albumin, and changes in the body composition. Neonatal pigs still have immature albumin levels which reach adult values around 1 year of age (Gasthuys et al., 2016). Low amounts of albumin leads thus to a higher free fraction of IBU and a higher $V_{d}$. The body composition in pigs changes during development. Warnants et al. (2006) demonstrated that 4-10-week-old pigs had $10 \%$ fat, while 6 -month-old pigs had $>20 \%$ fat. Although the log octanolwater partition coefficient is 3.97 for ibuprofen, a decreased $\mathrm{V}_{\mathrm{d}}$ in obese adults compared to adults with a normal BW for IBU was observed and attributed to the body composition (Abernethy and Greenblatt, 1985). A lower $V_{d}$ in 6-7 months old pigs with a high fat content is thus considered similar to human. Nevertheless, non-weight-normalized $\mathrm{V}_{\mathrm{d}}$ did show an allometric relationship with weight (Supplementary Figure S2). The observed developmental differences in $\mathrm{Cl}$ and $\mathrm{V}_{\mathrm{d}}$, which are not linearly related to BW, emphasize the importance of evaluating non-weight-normalized PK parameters.

Only limited sex differences in the 6-7-month-old pigs were noticed. After the first oral dose, $\mathrm{k}_{\mathrm{a}}$ of total IBU was significantly higher in the females compared to the males. A clear hypothesis for this observation cannot be put forward. Next to that, the $\mathrm{AUC}_{I V, 0 \rightarrow 3}$ of total IBU was significantly higher in the males compared to the females. This might be due to the observed similar differences in $\mathrm{AUC}_{I V, 0 \rightarrow 3}$ for R-IBU. A higher AUC could suggest a slower R-to-S conversion. Nevertheless, no significant sex differences in $\mathrm{Cl}$ or $\mathrm{Cl} \mathrm{R}$ to $\mathrm{S}$ were observed.

Several studies in children demonstrated a relationship between $\mathrm{Cl}$ and $\mathrm{V}_{\mathrm{d}}$ and age (Supplementary Table S3). While Brown et al. (1992) observed a decreasing $\mathrm{Cl}$ and $\mathrm{V}_{\mathrm{d}}$ with age, Har-Even et al. (2014) and Khalil et al. (2017) observed an increasing $\mathrm{Cl}$ and $\mathrm{V}_{\mathrm{d}}$ with age/weight. The $\mathrm{Cl}$ in children was $10.3,19.5,32.8$, and $81.3 \mathrm{~mL} / \mathrm{min}$ for children aged 1,6 months 2, 2-6, and 6-16 years, respectively (Khalil et al., 2017). This is 
similar to the increasing whole body $\mathrm{Cl}$ observed in the current study, namely $6.8,25.9,111.1$, and $307.5 \mathrm{~mL} / \mathrm{min}$ for the 1 week-, 4-week-, 8-week-, and 6-7-month-old pigs, respectively. Similarly, $\mathrm{V}_{\mathrm{d}}$ in the pediatric age groups as mentioned above increased from $1053.7 \mathrm{~mL}$ in the 1-month-old infants to $10314.2 \mathrm{~mL}$ in children aged $6-16$ years. In pigs, $\mathrm{V}_{\mathrm{d}}$ increased as well, namely $907.3 \mathrm{~mL}$ in the 1-week-old pigs toward $19527.1 \mathrm{~mL}$ in the 6-7-months old pigs. This limited available pediatric data might suggest that the juvenile pig could be a suitable animal model for the pediatric population. However, further research is required to evaluate allometric scaling or other in silico tools. Moreover, more thorough PK studies are warranted where all pediatric data are described in the most comprehensive way, since often only the mean parameters of a wide age range are provided.

\section{Enantiomeric Pharmacokinetics of lbuprofen in the Growing Piglet}

The developmental PK of R- and S-IBU showed great differences most likely attributed to their enantioselective behavior. Both enantiomers were rapidly absorbed in all age groups, but the $\mathrm{C}_{\max , \mathrm{S}}$ and $\mathrm{T}_{\max , \mathrm{S}}$ were always higher/later compared to R-IBU. This is probably due to the systemic stereochemical conversion of R-IBU to S-IBU. Pigs are able to perform chiral inversion, as was shown after administration of the pure R-enantiomer of ketoprofen (Neirinckx et al., 2011b). The rate of stereochemical conversion of R-IBU decreased with age and was the highest in the 1-week-old piglets (Table 2). Since no urine was collected, it was not possible to determine the fraction of the dose converted. In human adults, the conversion rate was estimated to be $0.53-$ $0.82 \mathrm{~mL} / \mathrm{min} / \mathrm{kg}$ with a total fraction of 0.48 to 0.68 of the dose being converted (Rudy et al., 1991; Tan et al., 2003). In the pediatric population, very limited data is available regarding the conversion of IBU. Gregoire et al. (2008) estimated that $17 \%$ of R-IBU was converted to S-IBU in premature newborn infants. Rey et al. (1994) found the plasma concentrations of S-IBU always to be smaller than those of R-IBU probably due to impaired conversion or higher S-IBU clearance. It should be noted however that these infants were treated with IBU during surgery recovery, meaning that the after-effects of the anesthesia could possibly have affected the PK of IBU. Generation of more pediatric data is warranted to obtain a full developmental profile of the stereochemical conversion of R- to S-IBU since the results of Rey et al. (1994) are currently generalized for the complete pediatric population although it only covers infants (Rey et al., 1994; Rainsford, 2009).

No significant differences could be found between R-IBU and S-IBU regarding $\mathrm{F}$. While $\mathrm{F}_{\mathrm{S}}$ did not change with age, $\mathrm{F}_{\mathrm{R}}$ was significantly lower at 4 weeks of age compared to the 1 -week-old piglets. This might be an indication of presystemic conversion. Nevertheless, since no differences in PK parameters between IV and PO administration at 4 weeks of age were observed, it is highly doubtful if pre-systemic conversion does actually occur. The 4 -week-old pigs were weaned at arrival at the test facility and this could have had an influence on $F_{R}$. It is known that weaning activates several immune and inflammatory responses, which are likely a cause of small intestine atrophy (Bomba et al., 2014; Cao et al., 2018). Consequently, this might lead to enantioselective absorption with a preference for the S-enantiomer or faster pre-systemic elimination of R-IBU. Enantioselective absorption, however, has not yet been reported in literature.

The $\mathrm{Cl}$ of $\mathrm{R}$ - and S-IBU changed differently during the first 4 weeks of life. While $\mathrm{Cl}$ of R-IBU $\left(\mathrm{Cl}_{\mathrm{R}}\right)$ decreased, $\mathrm{Cl}$ of S-IBU $\left(\mathrm{Cl}_{S}\right)$ increased during these first 4 weeks. These developmental changes in porcine $\mathrm{Cl}$ are similar to pediatric data generated by Dong et al. (2000), where a decreasing $\mathrm{Cl}_{\mathrm{R}}$ with age and a higher weight normalized $\mathrm{Cl}_{\mathrm{R}}$ in children (2-13 years) compared to adults was found. The $\mathrm{S}$-enantiomer showed no correlation with age in these children.

Both enantiomers had the lowest $V_{d}$ at 6-7 months which could be attributed to the body composition as discussed above. After IV administration, $V_{R}$ was higher compared to $V_{S}$ in the 1 -week-old piglets ( 329.9 versus $248.5 \mathrm{~mL} / \mathrm{kg}$ respectively). Neonatal pigs still have immature albumin concentrations, making them more subject to differences in enantioselective protein binding. In human, the protein binding is competitive and enantioselective, with a higher affinity of R-IBU for albumin compared to S-IBU. This leads to a higher free fraction of S-IBU and consequently a higher $V_{S}$ in human. The results in the neonatal pigs however, suggest otherwise, namely higher albumin affinity for S-IBU (Hao et al., 2005). This hypothesis should be verified with protein binding experiments using both racemic ibuprofen and the individual enantiomers.

The enantiomeric differences in $\mathrm{T}_{1 / 2}$ were also comparable to human. In premature new-born infants, $\mathrm{T}_{1 / 2, S}$ was found to be longer than $\mathrm{T}_{1 / 2, R}$ (2,058 vs. $498 \mathrm{~min}$ on post-natal day 1 , Supplementary Table S3), which was also observed in the 1week-old piglets (99.2 vs. $22.6 \mathrm{~min}$ ) (Gregoire et al., 2008). The differences in porcine $\mathrm{T}_{1 / 2}$ became smaller with aging, as was also observed in human by Kelley et al. (1992), Dong et al. (2000), and Tan et al. (2003). Rey et al. (1994) on the other hand, found no enantiomeric differences in $\mathrm{T}_{1 / 2}$.

While the PK of the IBU enantiomers in the growing pig does show some similarities with the available human data, thorough comparison is impossible due to the lack of extensive PK studies evaluating both enantiomers in the complete pediatric population. Further research is warranted.

\section{Multiple Oral Dosing}

Consecutive oral dosing for 5 days did alter the enantioselective PK characteristics in growing piglets although no accumulation was observed. In children aged 4-11 years, also no IBU accumulation occurred after five oral doses of an IBUpseudoephedrine suspension every $6 \mathrm{~h}$. However, the PK characteristics were only determined after the fifth dose (Gelotte et al., 2010). In humans, the absorption of IBU tablets is believed to be determined by gastric emptying and the gastrointestinal transit time (Neirinckx et al., 2011a; Koenigsknecht et al., 2017). The current study used a suspension which was apparently not influenced by the fed state, as demonstrated by the absent differences in $\mathrm{T}_{\max }$ or $\mathrm{k}_{\mathrm{a}}$ between the first and last oral administration of the multiple oral dosing study. However, $\mathrm{C}_{\max , \mathrm{R}}$ and $\mathrm{F}_{\mathrm{R}}$ were decreased, except for the 1-week-old pigs 
$\left(F_{R}\right)$ and 6-7 months old pigs $\left(C_{\max , R}\right)$, which could mean that pre-systemic conversion or elimination occurred upon multiple dosing. Unfortunately, no extensive similar human PK data are available. Most human PK trials are single dose only or the PK studies were only performed at the start or end of the trial when multiple dosing was done, but not on both occasions as in the current study.

\section{Safety Profile of Ibuprofen}

Since only the duodenum and jejunum of the 1-week-old IBU group showed a higher inflammatory response, while the other significant higher responses were observed in the control group, IBU was considered to be safe to administer to pigs from 1week-old till 6-7-months of age. This is consistent with the low incidence of adverse events observed in children (Rainsford, 2009; de Martino et al., 2017; Ziesenitz et al., 2017). Regarding renal safety, elevated eRPF was observed in the 4-week- and 67-months-old pigs, but no differences in GFR were observed. This is in contrast with the results from Junot et al. (2017) where both a decreased GFR and renal blood flow were observed after administration of ketoprofen to pigs weighing $25-32 \mathrm{~kg}$. It would be expected that NSAIDs such as IBU, decrease GFR and eRPF due to their inhibitory effect on the formation of vasodilatating prostaglandins (Kim, 2008). However, since pigs are able to acetylate $\mathrm{PAH}$, this route of elimination needs to be taken into account when determining the true RPF (Troncy et al., 1997). The eRPF determined in the current study represents both renal and metabolic clearance. The increased eRPF could be attributed to an increased acetylation capacity instead of an IBU-related vasodilatation which would be contradictory. In conclusion, 5 days dosing of IBU did not alter the renal function of the piglets.

\section{CONCLUSION}

The developmental and enantioselective PK of IBU in the growing piglet was demonstrated. Multiple oral dosing did affect some PK parameters, decreased the bioavailability of R-IBU and was shown to be safe. Age did affect the rate of stereochemical conversion. The limited human $\mathrm{PK}$ data available showed a similar increase in $\mathrm{Cl}$ and $\mathrm{V}_{\mathrm{d}}$ of total ibuprofen as observed in the current study, suggesting the conventional pig as a suitable animal model to evaluate ibuprofen and possibly other NSAIDs. Nevertheless, more comprehensive pediatric data regarding the IBU enantiomers is warranted.

\section{REFERENCES}

Abernethy, D. R., and Greenblatt, D. J. (1985). Ibuprofen disposition in obese individuals. Arthritis Rheum. 28, 1117-1121. doi: 10.1002/art.178028 1006

Baldrick, P. (2018). ). Juvenile animal testing: assessing need and use in the drug product label. Ther. Innov. Regul. Sci. 52, 641-648. doi: 10.1177/ 2168479017750129

Bomba, L., Minuti, A., Moisá, S. J., Trevisi, E., Eufemi, E., Lizier, M., et al. (2014). Gut response induced by weaning in piglet features marked changes in immune

\section{ETHICS STATEMENT}

The current study was approved by the ethical committee of the Faculties of Veterinary Medicine and Bioscience Engineering of Ghent University (EC2016/105). Care and use of the animals were in full compliance with the national and European legislation on animal welfare and ethics (Flemisch Government 2017) and (Eur-Lex, 2010).

\section{AUTHOR CONTRIBUTIONS}

JM, JVW, EG, SC, and MD contributed conception and design of the study. JM performed the animal trials, bioanalytical, histological, pharmacokinetic, statistical analysis, and wrote the first draft of the manuscript. TvB, SS, GA, and AM performed surgical procedures necessary for this study. KC aided in the histological analysis. $\mathrm{MD}$ and RG aided in the pharmacokinetic analysis. All authors contributed to manuscript revision, read and approved the submitted version.

\section{FUNDING}

This study was funded by the Agency for Innovation by Science and Technology in Flanders and the Agency for Innovation and Entrepreneurship in Flanders (IWT, SB141427).

\section{ACKNOWLEDGMENTS}

The authors thank the SafePedrug consortium, www.safepe drug.eu. The help of the colleagues during the animal and analytical experiments was gratefully appreciated. Phoenix ${ }^{\circledR}$ software was provided by Certara through their Centers of Excellence program.

\section{SUPPLEMENTARY MATERIAL}

The Supplementary Material for this article can be found online at: https://www.frontiersin.org/articles/10.3389/fphar. 2019.00505/full\#supplementary-material

and inflammatory response. Funct. Integr. Genom. 14, 657-671. doi: 10.1007/ s10142-014-0396-x

Brown, R. D., Wilson, J. T., Kearns, G. L., Eichler, V. F., Johnson, V. A., and Bertrand, K. M. (1992). Single-dose pharmacokinetics of ibuprofen and acetaminophen in febrile children. J. Clin. Pharmacol. 32, 231-241. doi: 10.1002/j.1552-4604.1992.tb03831.x

Califf, R. (2016). Best Pharmaceuticals for Children Act and Pediatric Research Equity Act. Silver Spring, MD: Food and Drug Administration.

Cao, S. T., Wang, C. C., Wu, H., Zhang, Q. H., Jiao, L. F., and Hu, C. H. (2018). Weaning disrupts intestinal antioxidant status, impairs intestinal barrier and 
mitochondrial function, and triggers mitophagy in piglets. J. Anim. Sci. 96, 1073-1083. doi: 10.1093/jas/skx062

de Martino, M., Chiarugi, A., Boner, A., Montini, G., and De’ Angelis, G. L. (2017). Working towards an appropriate use of ibuprofen in children: an evidencebased appraisal. Drugs 77, 1295-1311. doi: 10.1007/s40265-017-0751-z

De Schaepdrijver, L., Bailey, G., Coogan, T., and Ingram-Ross, J. (2013). “"Juvenile animal toxicity assesments: decision strategies and study design," in Pediatric Drug Development: Concepts and Applications, eds A. E. Mulberg, D. Murphy, J. Dunne, and L. L. Mathis (Hoboken, NJ: John Wiley \& Sons, Ltd.).

Dhondt, L., Croubels, S., De Cock, P., De Paepe, P., De Baere, S., and Devreese, M. (2019). Development and validation of an ultra-high performance liquid chromatography-tandem mass spectrometry method for the simultaneous determination of iohexol, p-aminohippuric acid and creatinine in porcine and broiler chicken plasma. J. Chromatogr. B 1117, 77-85. doi: 10.1016/j.jchromb. 2019.04.017

Dong, J. Q., Ni, L., Scott, C. S., Retsch-Bogart, G. Z., and Smith, P. C. (2000). Pharmacokinetics of ibuprofen enantiomers in children with cystic fibrosis. J. Clin. Pharmacol. 40, 861-868. doi: 10.1177/0091270002200 9594

EMA (2017). State of Paediatric Medicines in the EU: 10 Years of the EU Paediatric Regulation. Amsterdam: EMA.

Eur-Lex (2010). Directive 2010/63/EU of the European Parliament and the Council of 22 September 2010 on the Protection of Animals used for Scientific Purposes. Brussels: European Union.

Flemish Government (2017). Flemish Decree of 17 February 2017 on the Amendment of the Belgian Royal Decree of 29 May 2013 on the Protection of Animals used for Scientific Purposes and the Belgian Royal Decree of 21 November 1996 for the Determination of Compensation of Transport and Accomodation Costs for Persons not Belonging to the Administration and Part of Some Bodies put Together for the Royal Decree of 14 August 1986 Concerning the Protection and Welfare of Animals. Brussels: Flemish Government.

Gad, S. C. (2015). Animal Models in Toxicology, 3rd Edn. Boca Raton, FL: CRC Press.

Gasthuys, E., Devreese, M., Millecam, J., Sys, S., Vanderperren, K., Delanghe, J., et al. (2017a). Postnatal maturation of the glomerular filtration rate in conventional growing piglets as potential juvenile animal model for preclinical pharmaceutical research. Front. Pharmacol. 8:431. doi: 10.3389/fphar.2017. 00431

Gasthuys, E., Schauvliege, S., van Bergen, T., Millecam, J., Cerasoli, I., Martens, A., et al. (2017b). Repetitive urine and blood sampling in neonatal and weaned piglets for pharmacokinetic and pharmacodynamic modelling in drug discovery: a pilot study. Lab. Anim. 51, 498-508. doi: 10.1177/ 0023677217692372

Gasthuys, E., Vandecasteele, T., De Bruyne, P., Walle, J. V., De Backer, P., Cornillie, P., et al. (2016). The potential use of piglets as human pediatric surrogate for preclinical pharmacokinetic and pharmacodynamic drug testing. Curr. Pharm. Des. 22, 4069-4085. doi: 10.2174/138161282266616030311 1031

Gasthuys, E., Vermeulen, A., Croubels, S., Millecam, J., Schauvliege, S., van Bergen, T., et al. (2018). Population pharmacokinetic modeling of a desmopressin oral lyophilisate in growing piglets as a model for the pediatric population. Front. Pharmacol. 9:41. doi: 10.3389/fphar.2018.00041

Geboes, K., Riddell, R., Ost, A., Jensfelt, B., Persson, T., and Löfberg, R. (2000). A reproducible grading scale for histological assessment of inflammation in ulcerative colitis. Gut 47, 404-409. doi: 10.1136/gut.47.3.404

Gelotte, C. K., Prior, M. J., Pendley, C., Zimmerman, B., and Lavins, B. J. (2010). Multiple-dose pharmacokinetics and safety of an ibuprofen-pseudoephedrine cold suspension in children. Clin. Pediatr. 49, 678-685. doi: 10.1177/ 0009922810363153

Gregoire, N., Desfrere, L., Roze, J. C., Kibleur, Y., and Koehne, P. (2008). Population pharmacokinetic analysis of Ibuprofen enantiomers in preterm newborn infants. J. Clin. Pharmacol. 48, 1460-1468. doi: 10.1177/009127000832 3752

Hao, H., Wang, G., and Sun, J. (2005). Enantioselective pharmacokinetics of ibuprofen and involved mechanisms. Drug Metab. Rev. 37, 215-234. doi: 10.1081/DMR-200047999

Har-Even, R., Stepensky, D., Britzi, M., Soback, S., Chaim, A. B., Brandriss, N., et al. (2014). Plasma and cerebrospinal fluid concentrations of ibuprofen in pediatric patients and antipyretic effect: pharmacokinetic-pharmacodynamic modeling analysis. J. Clin. Pharmacol. 54, 1023-1030. doi: 10.1002/jcph.307

Helke, K. L., and Swindle, M. M. (2013). Animal models of toxicology testing: the role of pigs. Expert Opin. Drug Metab. Toxicol. 9, 127-139. doi: 10.1517/ 17425255.2013 .739607

Hu, S. X. (2015). Impact of age on hepatic cytochrome P450 of domestic male Camborough-29 pigs. J. Vet. Pharmacol. Ther. 38, 150-159. doi: 10.1111/jvp. 12163

Junot, S., Keroak, S., Del Castillo, J. R. E., Ayoub, J. Y., Paquet, C., BonnetGarin, J. M., et al. (2017). Inhaled nitric oxide prevents NSAID-induced renal impairment in pseudo-normovolaemic piglets. PLoS One 12:e0179475. doi: 10.1371/journal.pone.0179475

Kelley, M. T., Walson, P. D., Edge, J. H., Cox, S., and Mortensen, M. E. (1992). Pharmacokinetics and pharmacodynamics of ibuprofen isomers and acetaminophen in febrile children. Clin. Pharmacol. Ther. 52, 181-189. doi: 10.1038/clpt.1992.128

Khalil, S. N., Hahn, B. J., Chumpitazi, C. E., Rock, A. D., Kaelin, B. A., and Macias, C. G. (2017). A multicenter, randomized, open-label, active-comparator trial to determine the efficacy, safety, and pharmacokinetics of intravenous ibuprofen for treatment of fever in hospitalized pediatric patients. BMC Pediatr. 17:42. doi: 10.1186/s12887-017-0795-y

Kim, G. H. (2008). Renal effects of prostaglandins and cyclooxygenase2 inhibitors. Electrolyte Blood Press 6, 35-41. doi: 10.5049/EBP.2008. 6.1 .35

Koenigsknecht, M. J., Baker, J. R., Wen, B., Frances, A., Zhang, H., Yu, A., et al. (2017). "In vivo dissolution and systemic absorption of immediate release ibuprofen in human gastrointestinal tract under fed and fasted conditions. Mol. Pharm. 14, 4295-4304. doi: 10.1021/acs.molpharmaceut. $7 \mathrm{~b} 00425$

Lanza, F. L., Royer, G. L., Nelson, R. S., Rack, M. F., and Seckman, C. C. (1985). Ethanol, aspirin, ibuprofen, and the gastroduodenal mucosa: an endoscopic assessment. Am. J. Gastroenterol. 80, 767-769.

Millecam, J., De Clerck, L., Govaert, E., Devreese, M., Gasthuys, E., Schelstraete, W., et al. (2018). The ontogeny of cytochrome P450 enzyme activity and protein abundance in conventional pigs in support of preclinical pediatric drug research. Front. Pharmacol. 9:470. doi: 10.3389/fphar.2018.00470

Neirinckx, E., Croubels, S., De Boever, S., Remon, J. P., Bosmans, T., Daminet, S., et al. (2011a). Species comparison of enantioselective oral bioavailability and pharmacokinetics of ketoprofen. Res. Vet. Sci. 91, 415-421. doi: 10.1016/j.rvsc. 2010.08.017

Neirinckx, E., Croubels, S., Remon, J. P., Devreese, M., De Backer, P., and Vervaet, C. (2011b). Chiral inversion of $\mathrm{R}(-)$ to $\mathrm{S}(+)$ ketoprofen in pigs. Vet. J. 190, 290-292. doi: 10.1016/j.tvjl.2010.10.005

Rainsford, K. D. (2009). Ibuprofen: pharmacology, efficacy and safety. Inflammopharmacology 17, 275-342. doi: 10.1007/s10787-009-0016-x

Rainsford, K. D. (2011). Fifty years since the discovery of ibuprofen. Inflammopharmacology 19, 293-297. doi: 10.1007/s10787-011-0103-7

Rey, E., Pariente-Khayat, A., Gouyet, L., Vauzelle-Kervroëdan, F., Pons, G., D'Athis, P., et al. (1994). Stereoselective disposition of ibuprofen enantiomers in infants. Br. J. Clin. Pharmacol. 38, 373-375. doi: 10.1111/j.1365-2125.1994. tb04369.x

Rudy, A. C., Knight, P. M., Brater, D. C., and Hall, S. D. (1991). Stereoselective metabolism of ibuprofen in humans: administration of R-, S- and racemic ibuprofen. J. Pharmacol. Exp. Ther. 259, 1133-1139.

Swindle, M. M., Makin, A., Herron, A. J., Clubb, F. J., and Frazier, K. S. (2012). Swine as models in biomedical research and toxicology testing. Vet. Pathol. 49, 344-356. doi: 10.1177/0300985811402846

't Jong, G. (2014). "Pediatric development: physiology, enzymes, drug metabolism, pharmacokinetics and pharmacodynamics," in Pediatric Formulations. AAPS Advances in the Pharmaceutical Sciences Series, Vol. 11, eds D. Bar-Shalom and K. Rose (New York, NY: Springer).

Tan, S. C., Patel, B. K., Jackson, S. H., Swift, C. G., and Hutt, A. J. (2003). Influence of age on the enantiomeric disposition of ibuprofen in healthy volunteers. Br. J. Clin. Pharmacol. 55, 579-587. doi: 10.1046/j.1365-2125.2003. 01806.x

Troncy, E., Francoeur, M., Salazkin, I., Yang, F., Charbonneau, M., Leclerc, G., et al. (1997). Extra-pulmonary effects of inhaled nitric oxide in swine with and without phenylephrine. Br. J. Anaesth. 79, 631-640. doi: 10.1093/bja/79.5.631 
Van den Broeke, A., Aluwé, M., Janssens, S., Wauters, J., Vanhaecke, L., Buys, N., et al. (2015). The effect of the MC4R gene on boar taint compounds, sexual maturity and behaviour in growing-finishing boars and gilts. Animal 9, 1688-1697. doi: 10.1017/S1751731115001135

Walthall, K., Cappon, G. D., Hurtt, M. E., and Zoetis, T. (2005). Postnatal development of the gastrointestinal system: a species comparison. Birth Defects Res. B Dev. Reprod. Toxicol. 74, 132-156. doi: 10.1002/bdrb. 20040

Warnants, N., Van Oeckel, M., De Paepe, M., Millet, S., and De Brabander, D. (2006). "Evolutie van de lichaamssamenstelling van big tot slachtvarken," in Proceedings of the Infonamiddag ILVO-DIER "Actuele Onderzoeksresultaten bij Éénmagigen, (Melle).

Yoshimatsu, H., Konno, Y., Ishii, K., Satsukawa, M., and Yamashita, S. (2016). Usefulness of minipigs for predicting human pharmacokinetics: prediction of distribution volume and plasma clearance. Drug Metab. Pharmacokinet. 31, 73-81. doi: 10.1016/j.dmpk.2015.11.001
Ziesenitz, V. C., Zutter, A., Erb, T. O., and van den Anker, J. N. (2017). Efficacy and safety of ibuprofen in infants aged between 3 and 6 months. Paediatr. Drugs 19, 277-290. doi: 10.1007/s40272-017-0235-3

Conflict of Interest Statement: The authors declare that the research was conducted in the absence of any commercial or financial relationships that could be construed as a potential conflict of interest.

Copyright (c) 2019 Millecam, van Bergen, Schauvliege, Antonissen, Martens, Chiers, Gehring, Gasthuys, Vande Walle, Croubels and Devreese. This is an open-access article distributed under the terms of the Creative Commons Attribution License (CC BY). The use, distribution or reproduction in other forums is permitted, provided the original author(s) and the copyright owner(s) are credited and that the original publication in this journal is cited, in accordance with accepted academic practice. No use, distribution or reproduction is permitted which does not comply with these terms. 